\title{
Neutron Flux Variation at the Inner Irradiation Channel of the Nigeria Research Reactor-1 (NIRR-1)
}

\author{
Y. Musa*, Y.A. Ahmed, Y.A. Yamusa and M. Tukur \\ Nuclear Science and Technology Section, Centre for Energy Research and Training, Ahmadu Bello \\ University, Zaria, Nigeria
}

\begin{abstract}
In order to ascertain the level of flux variation in one of the inner irradiation channels of the Nigeria Research Reactor-1 (NIRR-1), the irradiation container used for routine activation analysis was employed with copper wires as flux monitors. Measurements were carried out with these wires arranged in axial direction to determine the thermal neutron flux at selected positions using absolute foil activation method. Our results show that there exists a slight flux variation from one position to another ranging from $(4.57 \pm 0.24) \times 10^{11}$ to $(5.20 \pm 0.20) \times 10^{11} \mathrm{~cm}^{-2} \mathrm{~s}^{-1}$. Individual foil shows slight flux variation from one position to another in the same irradiation container but they all pointed toward a level of stability in spite of the recent installation of the cadmium lined irradiation channel. The values obtained in this work are in good agreement with the previously measured value of $(5.14 \pm 0.24) \times 10^{11} \mathrm{~cm}^{-2} \mathrm{~s}^{-1}$ after commissioning of NIRR-1. This shows that the cadmium lined installation does not affect the flux stability. In order to improve the accuracy of neutron activation analysis (NAA) using NIRR-1 facility, there is need for flux corrections to be made by miniature neutron source reactor (MNSR) users during NAA particularly long irradiation, where more than six samples are irradiated simultaneously in the same container.
\end{abstract}

Keywords: Nuclear Flux, Irradiation Channel, NAA. NIRR-1.

\section{INTRODUCTION}

The only Research Reactor in Nigeria is the Nigeria Research Reactor-1 (NIRR-1), which is a Miniature Neutron Source Reactor (MNSR) installed at the Centre for Energy Research and Training, Ahmadu Bello University, Zaria. The NIRR-1 was acquired extensively for soil fertility and geochemical mapping project in Nigeria and has also been used over the years for neutron activation analysis [1], with an increasing interests in the determination of cross section and trace elements in many fields of science and technology [2, 3]. In this perspective, NAA using reactor neutrons plays a vital role due to its high sensitivity and detection limits for many elements in a variety of matrices [4], but these could not be achieved without a proper knowledge of the neutron flux. For proper utilization of this reactor, parameters such as neutron flux, $\varphi$, thermal to epithermal flux ratio, $f$ and neutron spectrum shaping factor, $\alpha$, has to be monitored regularly.

The Nigeria Research Reactor-1 (NIRR-1) is a tool for neutron activation analysis and thermal neutrons caused the majority reactions of interest in the activation analysis, with the reaction rate being proportional to the neutron flux [5]. Any quantitative activation measurements will rely on the neutron flux of the reactor [6]. The distribution of the neutron flux

*Address correspondence to this author at the Nuclear Science and Technology Section, Centre for Energy Research and Training, Ahmadu Bello University, Zaria, Nigeria; Tel: +234 803604 2748;

E-mail: yahaya_ms@yahoo.com however varies from one sample position to the other and from one irradiation channel to the next depending on the reactor type, core configuration, axial and radial distribution of the neutrons. This distribution does not remain constant even over relatively short distances [7] i.e. the neutron flux falls off with distance in both vertical and horizontal directions away from the reactor core. However, the neutron flux in a particular irradiation channel will depend on its distance from the reactor core. Therefore, determination of accurate information on the thermal neutron flux values to which the sample is exposed was necessary to obtain the accurate elemental concentrations.

Neutron flux measurement can be done either by relative or absolute method, but the former does not provide an absolute value of neutron flux at various points. However, the latter provides the absolute neutron flux in the irradiation channel or at some positions in the capsule [8]. As reported earlier [9], this drawback of the relative method has prompted an investigation into information about neutron flux in the irradiation position, and the nuclear data concerning the target and product nuclide that would be required to calculate element masses from the gamma-ray spectrum. But recent developments have shown that uncertainties in nuclear data are the major source of systematic errors in activation analysis using absolute method [10]. However, developments in nuclear data and in measurements of neutron flux parameters allow uncertainties to be reduced to below 10\% [9].

An experimental method was designed in this work to obtain the thermal flux in the B2-inner irradiation 
channel with similar foil arrangement to the recent work done in the Ghana research reactor-1 (GHARR-1) [11]. For quantitative calibration in neutron activation analysis, several approaches exist; such as relative method, comparator method and absolute method. In this work, an absolute foil activation method is employed to determine the axial neutron flux distributions in this channel. When sample is irradiated with neutrons, the activation rates depend on the geometry effect due to irradiation position within the capsule, the variation and the differences within the irradiation site [3]. Neutron flux variation within the irradiation container could introduce an uncertainty in NAA if appropriate measures are not taken; hence, successful application of neutron activation analysis can only be guaranteed if flux monitoring is performed in a regular basis for analytical quality control. The neutron flux at B2 inner irradiation channel was reported to be $(5.14 \pm 0.24) \times 10^{11} \mathrm{~cm}^{-2} \mathrm{~s}^{-1}[12]$, but after more than 8 years of successful operation of the NIRR1 facilities and recently the installation of the epicadmium lined channel in the large outer irradiation channel (Figure 1) for epithermal activation analysis, we envisage the need to re-measure the flux in this channel to guarantee its application in neutron activation analysis with the aim of investigating its variation from one sample position to another in the axial direction.

\section{THEORETICAL CONSIDERATION}

The reaction rate in a thermal neutron flux of known density $n$ can be calculated from the knowledge of the cross section $\sigma_{0}$ at a particular velocity $v_{0}$, provided that $\sigma$ is proportional to $1 / v$. The thermal flux distribution $\Phi_{t h}(E)$ as a function of energy after the neutrons reach thermal equilibrium with the moderator atoms is Maxwellian distribution given by:

$\Phi_{t h}(E)=\frac{E}{E_{m}^{2}} \exp \left(-\frac{E}{E_{m}}\right)$

where $\Phi_{t h}(E)$ is the neutron flux at energy $E$, normalized to unit integral flux. $E_{m}=k T_{m}$ represents the neutron energy, corresponding to the most probable velocity $v_{0}$, and $k$ is the Boltzmann's constant.

In absolute method, the thermal neutron flux is given as [13];

$\varphi_{t h}=\frac{N_{p} M}{w N_{a} \gamma \theta \varepsilon_{p}} \frac{1}{\left(1-e^{-\lambda t_{i}}\right) e^{-\lambda t_{d}}} \frac{\lambda}{\left(1-e^{-\lambda t_{m}}\right) c \sigma_{e f f}}$

$N_{p}$ the net number of counts under the full-energy peak during counting time, $t_{m}, \mathrm{w}$ is the weight of irradiated element, $S=1-e^{-\lambda t_{i r}}$ the saturation factor, $D=e^{-\lambda t_{d}}$ the decay factor with $t_{d}$ being the decay time, $C=\left(1-e^{-\lambda t_{m}}\right) / \lambda t_{m}$ the measurement factor correcting for decay during the measurement time, $t_{m}, M$ the atomic weight, $\lambda$ is the decay constant, $\theta$ the isotopic abundance, $N_{a}$ the Avogadro's number, $\gamma$ the absolute gamma-ray emission probability, $\varepsilon_{p}$ the full energy peak detection efficiency, $c$ is the concentration of the analyte and $\sigma_{\text {eff }}$ is the effective neutron cross section in $\mathrm{cm}^{2}$ as defined below [13];

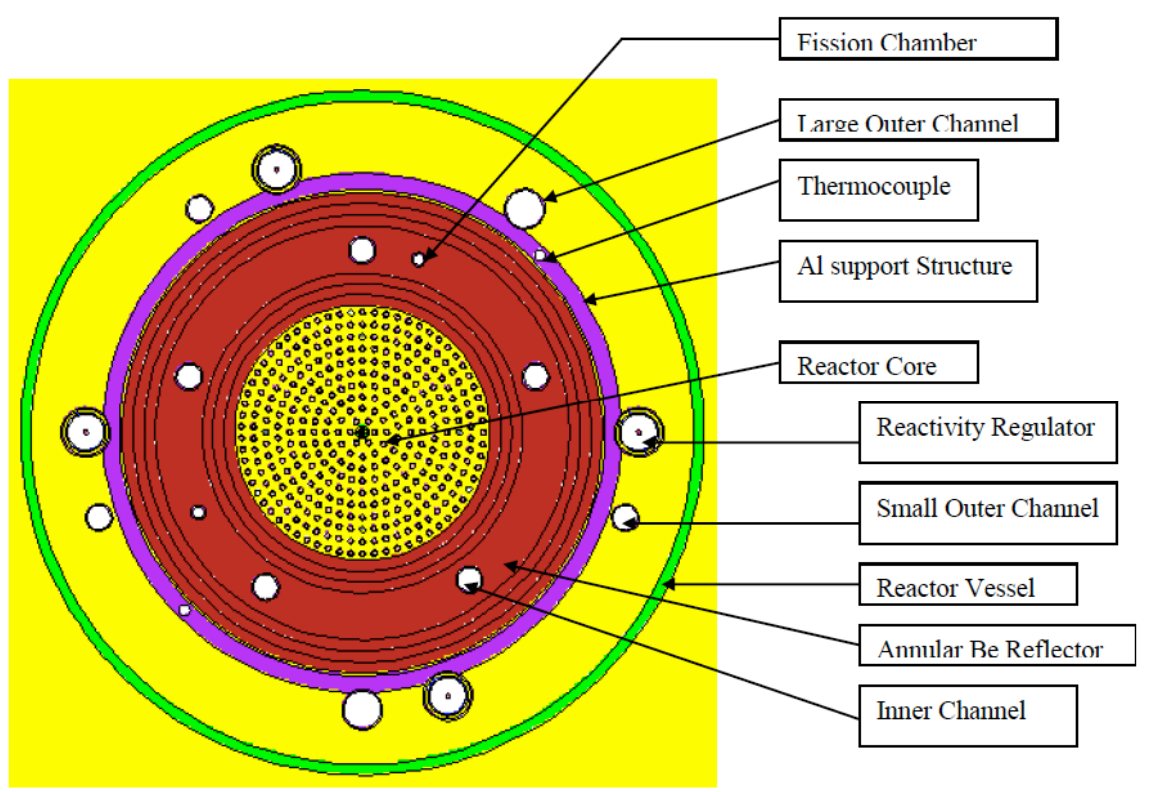

Figure 1: A geometric diagram of NIRR-1 in the $x-y$ plane from MCNP. 


$$
\sigma_{e f f}=\sigma_{0}\left(1+\frac{Q_{0}(\alpha)}{f}\right)
$$

Where $Q_{0}=I_{0} / \sigma_{0}$ is the ratio of resonance integral to thermal cross-section, $\alpha$ is a measure of the non-ideal epithermal neutron flux distribution, and $f$ is the thermal to epithermal neutron flux ratio.

For non-ideal situation, the $Q_{0}$ needs to be modified with an $\alpha$-dependent term because the $Q_{0}$-values are only valid for ideal spectra, and is not true for deviating spectra [14].

$Q_{0}(\alpha)=\frac{I_{0}(\alpha)}{\sigma_{t h}}=\frac{Q_{0}-0.429}{E_{r}^{\alpha}}+\frac{0.429}{(2 \alpha+1) E_{c d}^{\alpha}}$

For non-ideal conditions, the resonance integral $I_{0}$, must also be modified with an $\alpha$-dependent term, hence $I_{0}(\alpha)$ values should be used instead of $I_{0}[15]$.

$$
\begin{aligned}
& I(\alpha)=\left[\frac{I_{0}-0.426 \sigma_{0}}{\left(\bar{E}_{r}\right)^{\alpha}}+\frac{0.426 \sigma_{0}}{(2 \alpha+1)\left(E_{C d}\right)^{\alpha}}\right] \\
& E_{a}^{\alpha}=\int_{E_{C d}}^{\infty} \alpha(E) \frac{E_{a}^{\alpha}}{E^{1+\alpha}} d E
\end{aligned}
$$

Where $\left(E_{r}\right)^{\alpha}=$ effective resonance energy, $E_{a}^{\alpha}=1 \mathrm{eV}-$ arbitrary energy, $E_{C d}^{\alpha}=0.55 \mathrm{eV}$ - effective cadmium cut-off energy, $\sigma_{0}=2200 \mathrm{~m} / \mathrm{s}(n, \gamma)$ crosssection and $\alpha=$ an experimentally determinable characteristics of the reactor channel.

In gamma measurements of solid samples using $\mathrm{HPGe}$ detectors, it is of paramount importance to obtain the full energy peak efficiency in the calibrating geometry as a function of $\gamma$-emission energy $E_{\gamma}$.

$\varepsilon_{p}\left(E_{\gamma}\right)=\frac{N_{\gamma}}{t_{r} P A_{0} \exp \left(\frac{\Delta t}{\tau}\right)}$

Where $\boldsymbol{N}_{\gamma}$ is the number of counts in the photopeak, $\boldsymbol{t}_{\boldsymbol{r}}$ is the real time taken for the run data, $\boldsymbol{P}$ is the branching ratio corresponding to the energy, $\boldsymbol{A}_{\boldsymbol{0}}$ is the activity of the source on the reference date, $\Delta \boldsymbol{t}$ is the time elapse since calibration up to measurement. $\tau$ is the mean life time ( $\tau=\frac{1}{\lambda}$ where $\lambda$ is the decay constant)

\section{MATERIALS AND METHOD}

The activation material used was selected based on the purpose and conditions of the experiment, which required that the detecting material should be easy to acquire, have stable chemical properties and appropriate activation cross section and a proper half life [8]. Since cross-section spectra are similar in shape for a given type of neutron interaction, it is recommended not to choose specific interactions based on foils. Factors such as energy response, environmental conditions, exposure time and counting method were also taken into consideration.

Copper wire (99.99\% purity) was used for this work due to its availability amongst others, high crosssections for thermal neutrons compared to materials like Mo-99 and $\mathrm{Zn}-65$, and the required nuclear data parameters are obtainable from nuclear data table as shown in Table $1[16,17]$. The thermal to epithermal flux ratio, $f$ and epithermal neutron flux shaping factor, $\alpha$ values for B2-irradiation channel were obtained from earlier work [18], and reported as $19.2 \pm 0.5$ and -0.052 \pm 0.002 respectively. Values for $I_{0}(\alpha)$ and $Q_{0}(\alpha)$ were also determined from equations (4) and (5) respectively, while $I_{0}$ and $Q_{0}$ are obtainable from nuclear data [16].

The copper wires were arranged in axial directions in a typical irradiation container normally used for routine activation analysis. The wires were placed vertically as shown in Figure 2, labelled $X, Y$ and $Z$. After irradiation of $1 \mathrm{~min}$ in B2-inner channel, each wire was sectioned into three pieces to account for the axial flux profiles. A GEM- 30195 HPGe coaxial detector (ORTEC) consisting of MAESTRO Multi-channel analyzer (MCA) emulation software was calibrated and used for counting the induced radioactivity. Each of the sectioned copper wire was counted for 10 min at $15 \mathrm{~cm}$ from the detector's head, to obtain the net peak areas. The efficiency of the detector was determined from equation 6 using standard gamma-ray sources $\left({ }^{241} \mathrm{Am}\right.$, ${ }^{152} \mathrm{Eu},{ }^{137} \mathrm{Cs}$ and ${ }^{60} \mathrm{Co}$ ). From the efficiency curve, the

\begin{tabular}{|c|c|c|c|c|c|c|c|c|c|}
\hline Nuclide & Nuclear Reaction & $\theta(\%)$ & $\sigma_{\text {th }}($ barns $)$ & R.I (barns) & Product Half-life & $\mathrm{E} \gamma(\mathrm{keV})$ & $\gamma(\%)$ & $\mathbf{Q}_{0}$ & $E_{r}(e V)$ \\
\hline $\mathrm{Cu}$ & ${ }^{63} \mathrm{Cu}(\mathrm{n}, \gamma){ }^{64} \mathrm{Cu}$ & 69.17 & 4.28 & 4.88 & $12.7 \mathrm{~h}$ & 1345.77 & 0.48 & 1.1 & 1040 \\
\hline
\end{tabular}
photo peak efficiency was obtained. The $1345.77 \mathrm{keV}$

Table 1: Nuclear Data for Activation Material Used [17, 16] 
(a) Before irradiation

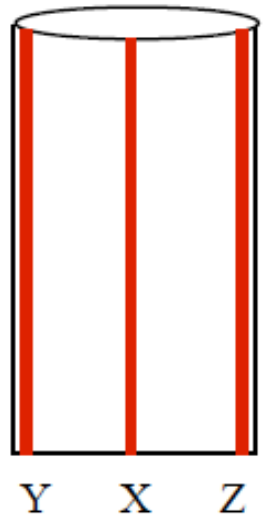

(b) After irradiation

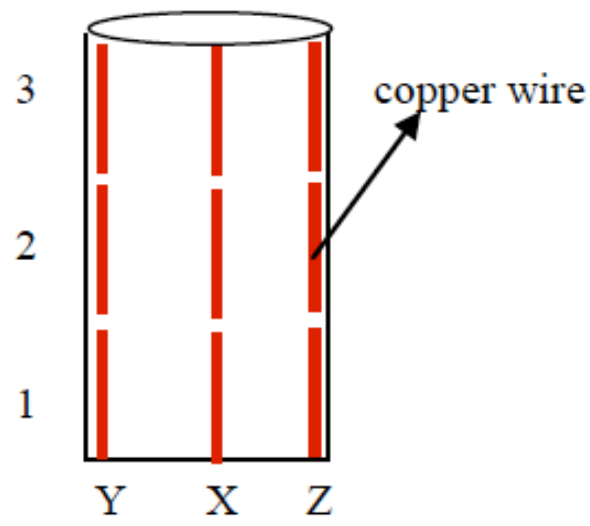

Figure 2: Schematic diagram showing the vertical wires before and after irradiation.

full energy peak from ${ }^{63} \mathrm{Cu}(\mathrm{n}, \gamma){ }^{64} \mathrm{Cu}$ reaction was employed because of its longer half-life (12.7 hrs) compared to $(5.14 \mathrm{~min})$ resulting from ${ }^{65} \mathrm{Cu}(\mathrm{n}, \gamma){ }^{66} \mathrm{Cu}$ reaction.

\section{RESULTS AND DISCUSSIONS}

The result for the efficiency calibration of the High Purity Germanium detector (HPGe) using standard gamma-ray sources is shown in Figure 3 . The photopeak efficiency of $1345.77 \mathrm{keV}$ peak was found from the efficiency curve and later used for calculations of the neutron fluxes. However, $1345.77 \mathrm{keV}$ peak was chosen and found to have less spectral interference when compared to $511 \mathrm{keV}$ and as a consequence little error propagation. This is because $511 \mathrm{keV}$ could be annihilation peak or from other radioisotopes such as
${ }^{24} \mathrm{Na}$ and ${ }^{49} \mathrm{Ca}-49$ which may possibly interfere with that of Cu-64 [5, 17].

Table 2 shows the axial neutron flux distribution and indicate a variation of $2 \%-4 \%$ along the vertical direction within the irradiation container. Figure 4 shows the overall axial neutron flux variation at positions $X, Y$ and $Z$ respectively. The axial neutron flux range from $4.57 \times 10^{11}$ to $5.20 \times 10^{11} \mathrm{~cm}^{-2} \mathrm{~s}^{-1}$ and the mean value in the container was found to be $4.90 \mathrm{x}$ $10^{11} \mathrm{~cm}^{-2} \mathrm{~s}^{-1} \cdot 0.1 \% \mathrm{Au}-\mathrm{Al}$ foil was also irradiated at the bottom of the irradiation container and the measured flux was $(4.53 \pm 0.02) \times 10^{11} \mathrm{~cm}^{-2} \mathrm{~s}^{-1}$. We infer that the observed variation in flux with position may be due to the relative position of the foil to the core, its vertical distance from the core and the decay time. Meanwhile, the measured values of both $\mathrm{Au}$ and Cu-wire are in

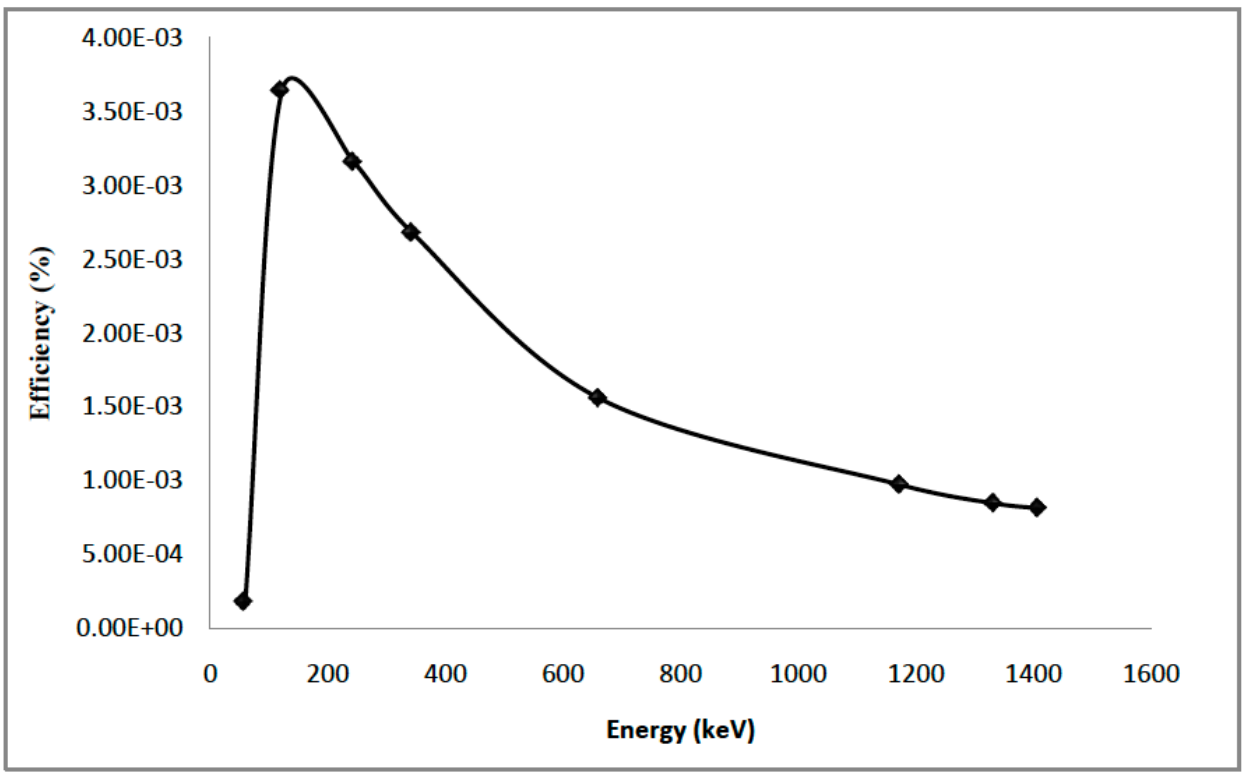

Figure 3: Graph of efficiency - energy function for the energy range $59.5 \mathrm{keV}-1408 \mathrm{keV}$. 
Table 2: Axial Flux Distribution in B2 Irradiation Channel

\begin{tabular}{|c|c|c|}
\hline Axial Position & Section & $\begin{array}{l}\text { Thermal Neutron Flux } \\
\quad \times 10^{11}\left(\mathrm{~cm}^{-2} \mathrm{~s}^{-1}\right)\end{array}$ \\
\hline \multirow[t]{3}{*}{ Centre (X) } & 1 & $4.92 \pm 0.18$ \\
\hline & 2 & $5.09 \pm 0.19$ \\
\hline & 3 & $4.83 \pm 0.18$ \\
\hline \multirow[t]{3}{*}{ Side $(Y)$} & 1 & $5.20 \pm 0.20$ \\
\hline & 2 & $4.92 \pm 0.20$ \\
\hline & 3 & $4.81 \pm 0.18$ \\
\hline \multirow[t]{3}{*}{ Side (Z) } & 1 & $4.96 \pm 0.19$ \\
\hline & 2 & $4.81 \pm 0.19$ \\
\hline & 3 & $4.57 \pm 0.21$ \\
\hline
\end{tabular}

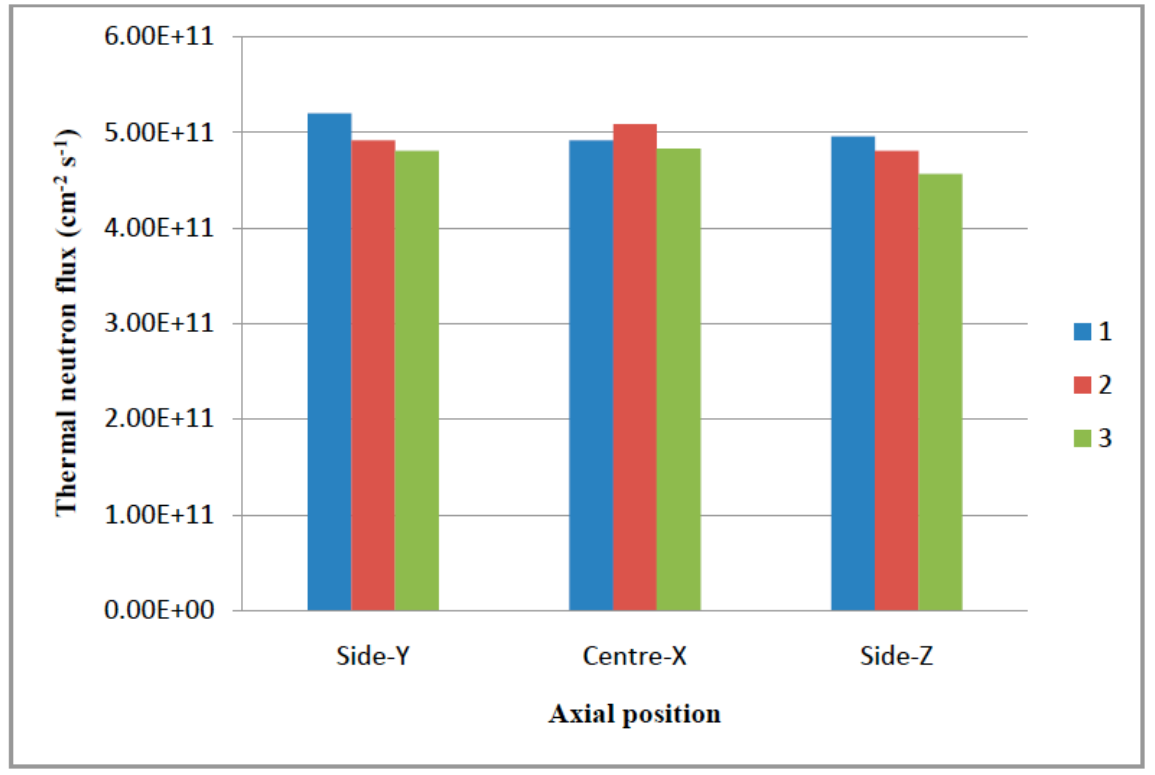

Figure 4: Axial neutron flux distribution within the irradiation container.

good agreement with the previously measured value [12].

\section{CONCLUSION}

Measurements of the axial flux distribution in the irradiation container at B2-irradiation channel have been carried out by foil activation method using ${ }^{63} \mathrm{Cu}(\mathrm{n}, \gamma){ }^{64} \mathrm{Cu}$ reaction, specifically by absolute method. Knowledge of the axial neutron flux in the core and the variation of the flux from one sample position to another are important in improving NAA technique. The axial neutron flux profiles indicate that variations occur from one position to another. The neutron flux for each of the positions measured can be used to predict the irradiation conditions of samples at those positions particularly during long irradiation in which many samples were jam-packed in one vial. This may facilitate flux corrections for the samples if need be. It can also be seen that even with the recent installation of the cadmium-liner in the outer channel of the reactor; the thermal neutron flux of the B2-channel has not deviated from $5.14 \times 10^{11} \mathrm{~cm}^{-2} \mathrm{~s}^{-1}$ measured earlier [12].

\section{ACKNOWLEDGEMENTS}

The authors are grateful to Prof. I. I. Funtua, Prof. M. O. A. Oladipo, Prof. S. A. Jonah Dr. B. B. M. Dewu and Prof. I. O. B. Ewa for their valuable contributions.

\section{REFERENCES}

[1] Jonah SA, Umar IM, Oladipo MOA, Balogun GI, Adeyemu DJ. Standardization of NIRR-1 irradiation and counting 
facilities for instrumental neutron activation analysis. Appl Rad Isot 2006; 64: 818-22.

http://dx.doi.org/10.1016/j.apradiso.2006.01.012

[2] Kapsimalis R, Landsberger S, Ahmed YA. The determination of uranium in food samples by Compton suppression epithermal neutron activation analysis. Appl Rad Isot 2009; 67: 2097-9.

http://dx.doi.org/10.1016/j.apradiso.2009.05.011

[3] Ahmed YA, Landsberger S, O'Kelly DJ, Braisted J, Gabdo H, Ewa IOB. Compton suppression method and epithermal NAA in the determination of nutrients and heavy metals in Nigeria food and beverages. Appl Rad Isot 2010; 68: 1909-14. http://dx.doi.org/10.1016/i.apradiso.2010.04.016

[4] Acharya RN, Nair AGC, Reddy AVR, Manohar SB. Validation of a neutron activation analysis method using $\mathrm{k}_{0}$ standardization. Appl Rad Isot 2002; 57: 391-8. http://dx.doi.org/10.1016/S0969-8043(02)00111-2

[5] Bode P, Blaauw M, Obrusnik I. Variation of neutron flux and related parameters in an irradiation container, in use with $\mathrm{k}_{0^{-}}$ based neutron activation analysis. J Radioanal Nucl Chem 1992; 157: 301-12.

http://dx.doi.org/10.1007/BF02047445

[6] Ahmed YA, Ewa IOB, Umar IM. Effective resonance energy and non-ideality of epithermal neutron flux distribution in neutron activation analysis. Nig J Phys 2002; 14: 82-5.

[7] Parry SJ. Activation spectrometry in chemical analysis. John Wiley \& Sons. 1991; New York.

[8] Guosheng Z. Absolute neutron flux measurement by gold foil activation method, MNSR Training Material. 1993; China Institute of Atomic Energy.

[9] Kafala SI, MacMahon TD. Comparison of neutron activation analysis methods. J Radioanal Nucl Chem 2007; 271: 50716.

http://dx.doi.org/10.1007/s10967-007-0238-6

[10] Ahmed YA, Ewa IOB, Umar IM. Variations in nuclear data and its impact on INAA. J Appl Sci 2006; 6: 1692-7. http://dx.doi.org/10.3923/jas.2006.1692.1697
[11] Abrefah RG, Nyarko BJB, Akaho EHK, Anim Sampong S, Sogbadji RBM. Axial and radial distribution of thermal and epithermal neutron fluxes in irradiation channels of the Ghana Research Reactor-1 using foil activation analysis. Ann Nucl Energy 2010; 37: 1027-35. http://dx.doi.org/10.1016/j. anucene.2010.04.017

[12] Jonah SA, Balogun GI, Umar IM, Mayaki MC. Neutron spectrum parameters in irradiation channel of the Nigeria Research Reactor-1 (NIRR-1) for the $\mathrm{k}_{0}-\mathrm{NAA}$ standardization. J Radioanal Nucl Chem 2005; 226: 83-8. http://dx.doi.org/10.1007/s10967-005-0873-8

[13] El-Khayatt AM. Elemental analysis of Egyptian crude oils by INAA using rabbit irradiation system at ETRR-2 reactor. Appl Rad Isot 2010; 68: 2438-42. http://dx.doi.org/10.1016/j.apradiso.2010.07.013

[14] Moen L, De Corte F, Simonits A, Wispelaere A, Hoste J. The effective resonance energy $E_{r}$ as a parameter for the correction of resonance integrals, $1 / \mathrm{E}^{(1+\alpha)}$ epithermal neutron spectra: tabulation of $E_{r}$ for 96 isotopes. J Analyt Chem 1979; 52: 379-87.

[15] Mustafa K, Haluk Y, Mustafa T, Atilla O. Measurement of thermal neutron cross-sections and resonance integrals for ${ }^{71} \mathrm{Ga}(\mathrm{n}, \gamma){ }^{72} \mathrm{Ga}$ and ${ }^{75} \mathrm{As}(\mathrm{n}, \gamma){ }^{76} \mathrm{As}$ by using ${ }^{241} \mathrm{Am}-\mathrm{Be}$ isotopic neutron source. Nucl Instr Meth Phys Resear A 2003; 501: 524-35.

http://dx.doi.org/10.1016/S0168-9002(03)00408-X

[16] Menno B. The $\mathrm{k}_{0}$-Consistent IRI Gamma-ray Catalogue for Instrumental Neutron Activation Analysis. 1996; ISBN 90 73861-32-2: Interfaculty Reactor Institute Delft.

[17] IAEA. Practical Aspects of Operating a Neutron Activation Analysis Laboratory, IAEA-TECDOC-564. 1990; ISSN 1011 . 4289: IAEA, Vienna.

[18] Jonah SA, Ibrahim YV, Akaho EHK. The determination of reactor spectrum-averaged cross-sections in miniature neutron source reactor facility. Appl Rad Isot 2008; 66: 137780.

http://dx.doi.org/10.1016/j.apradiso.2008.04.001 